\title{
Malignant Islet Cell Tumor with Sarcomatous Differentiation
}

Lyska Emerson, M.D., Lester J. Layfield, M.D., Russell Reiss, M.D., Sean Mulvihill, M.D., Joseph Holden, M.D.

Departments of Pathology (LE, LJL, JH) and Surgery (RR, SM), University of Utah Health Sciences Center, Salt Lake City, Utah

\begin{abstract}
Malignant mesenchymal neoplasms of the pancreas are rare and malignant islet cell tumors with sarcomatous dedifferentiation are rarer still. We present a case of malignant islet cell tumor with sarcomatous differentiation, which to our knowledge is only the second reported case showing such a combination of morphologic features. Clinically, the neoplasm was not hormonally active and immunohistochemical staining was negative for gastrin, glucagon, insulin and somatostatin. The sarcomatous component strongly reacted with an antibody directed against vimentin, and a minority of cells stained strongly with antisera directed against desmin and smooth muscle actin. The spindle cell component was nonreactive with antibodies directed against Factor VIII. The myogenous direction of differentiation in the present tumor is similar to that seen in the prior case report of malignant islet cell tumor with rhabdomyosarcomatous differentiation.
\end{abstract}

KEY WORDS: Carcinoid, Islet cell tumor, Pancreas, Sarcoma.

Mod Pathol 2001;14(11):1187-1191

Primary sarcomas of the pancreas are rare (1-7), with fewer than a dozen leiomyosarcomas and a single liposarcoma being reported in the English language literature. Rarer still are malignant islet cell tumors with sarcomatous differentiation. Only a single case report of such a combined neoplasm has to our knowledge appeared in the English language literature (8).

Copyright $(2001$ by The United States and Canadian Academy of Pathology, Inc.

VOL. 14, NO. 11, P. 1187, 2001 Printed in the U.S.A.

Date of acceptance: July 6, 2001.

Address reprint requests to: Lester Layfield, M.D., Department of Pathology, University of Utah Health Sciences Center, School of Medicine, 50 North Medical Drive, Salt Lake City, UT 84132; e-mail: layfield@ arup-lab.com; fax: 801-585-3831.
The histomorphologic spectrum of carcinoid tumors is wide with glandular morphologies, papillary structures, oncocytic changes, squamous and osseous metaplasia and spindle cell patterns being recognized (9-14). The spindle cell pattern described by Rosai et al. (14) appears to be unrelated to the sarcomatous changes seen in our case and that described by Ferreiro et al. (8). We report a case of pancreatic carcinoid (islet cell tumor) with focal myosarcomatous differentiation, which is to our knowledge only the second such case reported in the English language literature.

\section{CASE REPORT}

The patient, a 61-year-old Caucasian female, was followed at the University of Utah for gastroesophageal reflux of long duration controlled by Prilosec. An ultrasound of the abdomen was obtained 3 months before admission to investigate the patient's complaint of vague abdominal pain. A lesion was visualized around the liver, and endoscopy was performed, which revealed a Barrett's esophagus without dysplasia. A follow-up CT scan demonstrated a $10 \mathrm{~cm}$ heterogenous mass in the tail of the pancreas (Fig. 1) and three lesions in her liver. The patient's clinical history was otherwise unremarkable except for back pain, most noticeable when lying in bed. Physical examination failed to reveal icterus or lymphadenopathy. The patient underwent exploratory laparotomy with intraoperative biopsy and frozen section of the largest of the liver lesions. Frozen section revealed a hemangioma, and the pancreatic mass was then resected. The postoperative course was unremarkable, and no metastatic lesions have been detected in the immediate postoperative period.

\section{METHODS}

Representative tissue sections were taken from the specimen, fixed in $10 \%$ neutral buffered forma- 


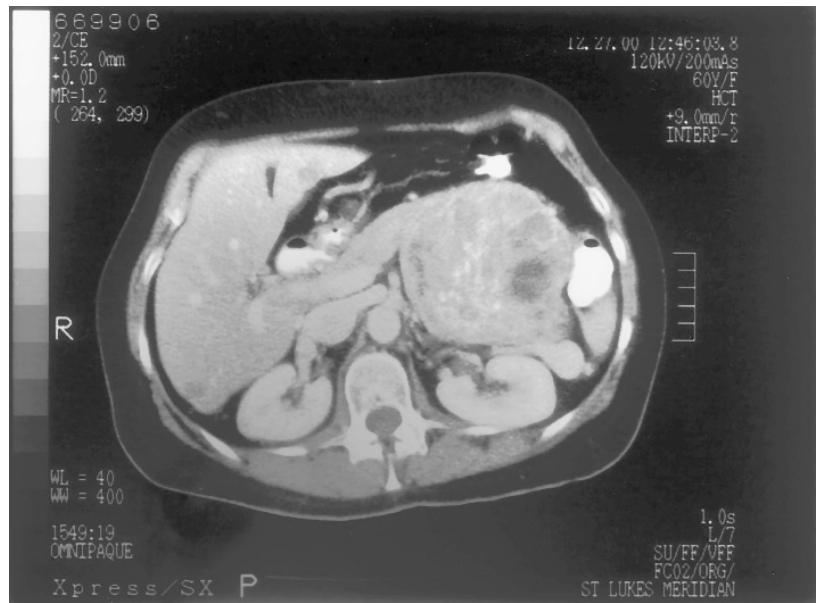

FIGURE 1. CT scan demonstrating large heterogeneous mass in the pancreas.

lin, paraffin embedded, and then stained by the hematoxylin and eosin method.

Immunohistochemistry was performed on dewaxed paraffin sections. Immunohistochemical stains for cytokeratin AE1/3, CAM 5.2, insulin, glucagon, chromogranin, gastrin, somatostatin, CD34, Factor VIII, smooth muscle actin and topoisomerase II were performed. Table 1 lists the sources of the antibodies and the dilutions used.

\section{PATHOLOGY}

The resection specimen was composed of a large ruptured pancreatic mass measuring $11.0 \times 9.0 \times$ $8.5 \mathrm{~cm}$ attached to a $10.0 \times 7.0 \times 2.5 \mathrm{~cm}$ portion of the tail of the pancreas. Also included in the specimen was an adrenal gland, the spleen and a $15.0 \times$ $5.5 \times 3.0 \mathrm{~cm}$ portion of the omentum. The mass was a lobulated structure covered by a loose connective tissue capsule. Cross sectioning of the mass revealed a well-circumscribed white mass with focal areas of calcification and extensive cystic degeneration and hemorrhage. The surrounding organs were unremarkable.

TABLE 1. Study Antisera Used: Sources and Dilutions

\begin{tabular}{llc}
\hline \multicolumn{1}{c}{ Antibodies } & \multicolumn{1}{c}{ Sources } & Dilutions \\
\hline Cytokeratin AE1/AE3 & $\begin{array}{c}\text { Boehringer Mannhein Corp., } \\
\text { Indianapolis, IN }\end{array}$ & $1: 2800$ \\
& \multicolumn{1}{c}{ Novocastra, Newcastle upon } & $1: 40$ \\
CAM 5.2 & \multicolumn{1}{c}{ Tyne, UK } & \\
Insulin & DAKO, Carpentina, CA & $1: 50$ \\
Glucagon & DAKO & $1: 100$ \\
Chromogranin & Boehringer Mannhein Corp. & $1: 8000$ \\
Gastrin & DAKO & $1: 600$ \\
Somatostatin & DAKO & $1: 50$ \\
CD34 & Biosource, Camarillo, CA & $1: 200$ \\
Factor VIII & DAKO & $1: 1600$ \\
Smooth muscle actin & DAKO & $1: 100$ \\
Topoisomerase II alpha & In house preparation & $1: 1000$ \\
\hline
\end{tabular}

Histologic sections revealed the majority of the neoplasms to have an insular pattern composed of nests of small uniform polygonal cells with an eosinophilic granular cytoplasm. The cell nests were surrounded by a fibrovascular stroma frequently showing dense collagenization (Fig. 2). The individual cell nuclei were relatively uniform in size and shape with smooth nuclear membranes and a granular (salt and pepper) chromatin pattern. Small nucleoli were present. Mitotic activity was scant. No evidence of differentiation toward a trabecular or tubular pattern was seen. This islet cell component presented a pushing margin abutting the surrounding uninvolved pancreas (Fig. 3).

Immunohistochemical staining for chromogranin demonstrated that the majority of cells decorated with this antibody (Fig. 4). Stains for gastrin, glucagon and somatostatin were all negative.

In one area of the tumor, a spindle cell component was identified (Fig. 5). This component was characterized by large spindle-shaped cells with enlarged hyperchromatic nuclei. These cells lay in poorly formed bundles or more frequently formed a "patternless" pattern. The nuclei were cigar-shaped with irregular nuclear membranes and relative clearing of the chromatin pattern. Small but distinct nucleoli were frequent.

Mitotic figures including atypical forms were common. The spindle cells irregularly infiltrated the surrounding nests of polygonal cells and extended along the fibrovascular septae of the islet cell component. Immunohistochemical stains for smooth muscle actin and desmin (Fig. 6) were strongly positive within a minority of the spindle cell component. Immunohistochemical stains for muscle specific actin, keratins AE1/3 and CAM 5.2, Factor VIII and CD34 did not decorate the neoplastic cells. Topoisomerase alpha II revealed

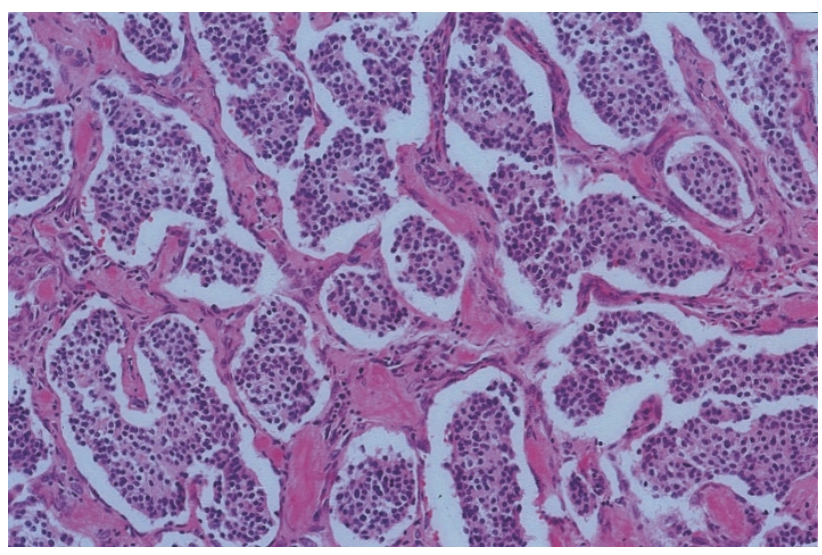

FIGURE 2. Insular growth pattern with nests of small, uniform polygonal cells surrounded by a fibrovascular stroma showing dense collagenization (hematoxylin and eosin stain, $\times 40$ ). 


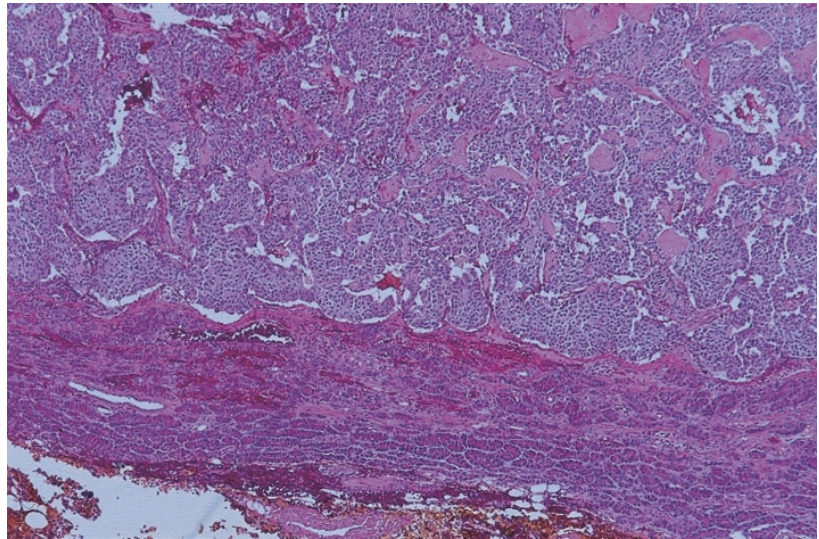

FIGURE 3. Low power view showing the pushing margin of the islet cell component adjacent to uninvolved pancreas (hematoxylin and eosin, $\times 16)$.

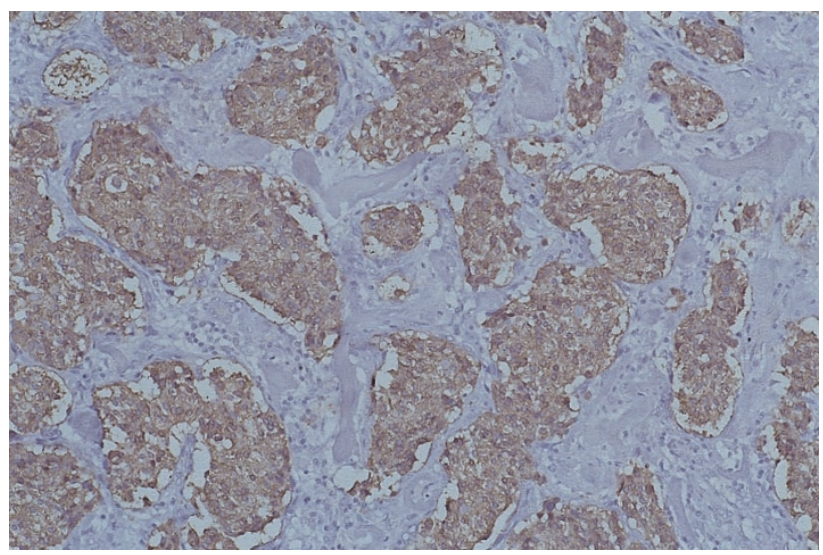

FIGURE 4. Endocrine cell component showing diffuse immunoreactivity for chromogranin (immunoperoxidase, $\times 40$ ).

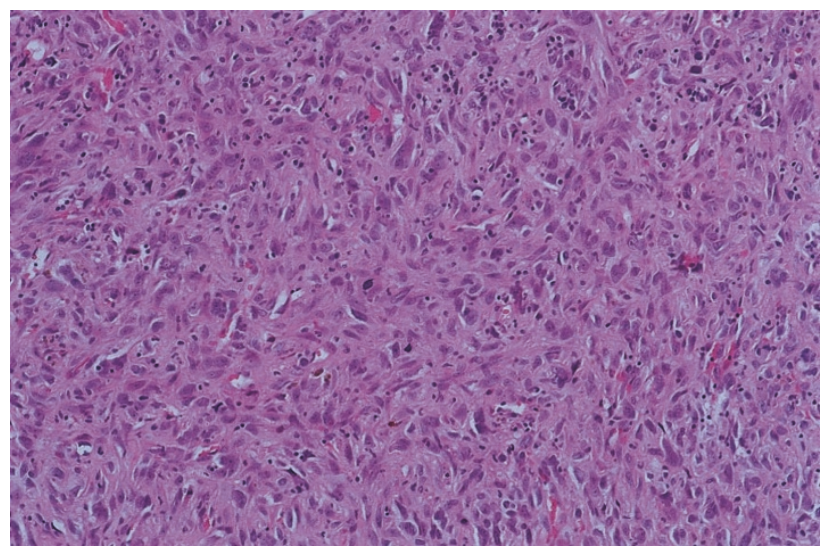

FIGURE 5. Focus of spindle cell component characterized by large, spindle-shaped cells with enlarged, hyperchromatic nuclei arranged in poorly formed bundles (hematoxylin and eosin, $\times 40$ ).

a high labeling index of $41 \%$ (Fig. 7). The topoisomerase stain revealed that the atypical spindle cell component extended into the fibrovascular connective tissue separating the nests of the islet cell tumor (Fig. 8).

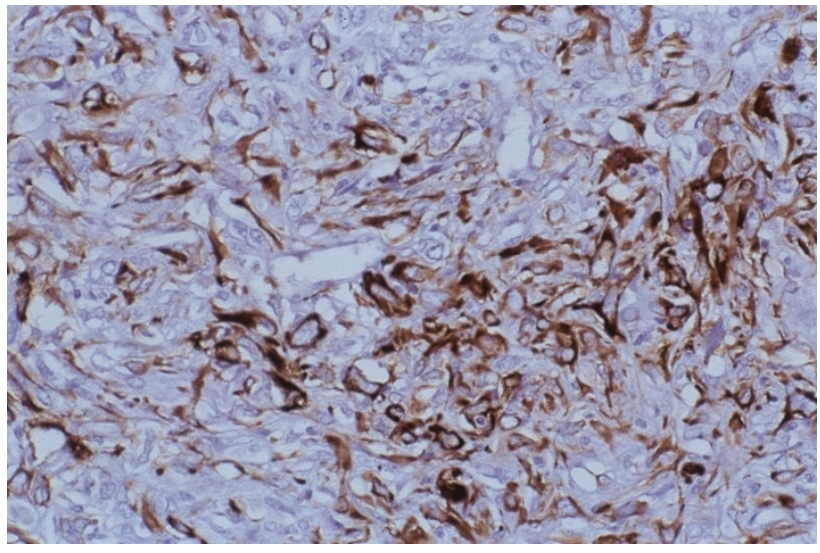

FIGURE 6. A minority of the anaplastic sarcoma component showing strong reactivity with antibodies directed against desmin (immunoperoxidase, $\times 80$ ).

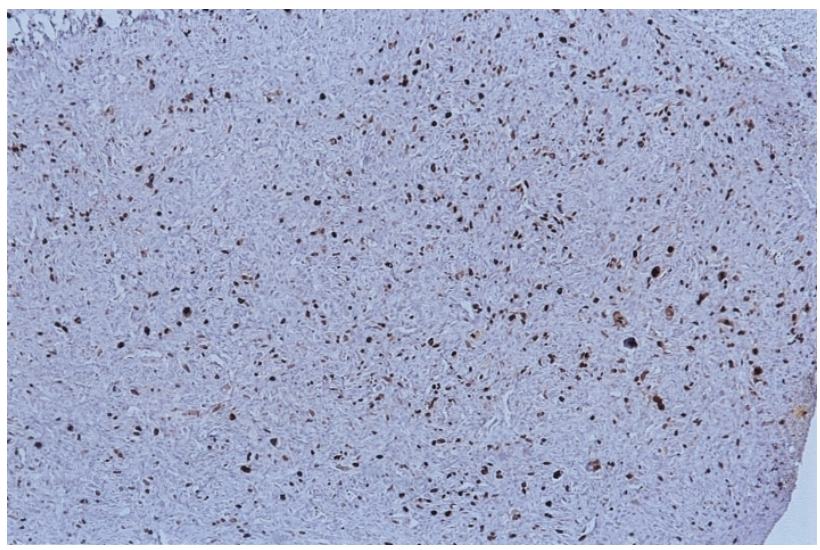

FIGURE 7. Immunoperoxidase staining of the sarcoma component showing frequent staining with antibodies directed against the proliferation marker, topoisomerase II alpha (immunoperoxidase, $\times 40$ ).

\section{DISCUSSION}

Primary sarcomas of the pancreas are relatively rare but have been well described within the literature (1-7). The majority appear to be leiomyosarcomas but liposarcomas have also been reported (1-7). True carcinosarcomas have been reported at a variety of sites including the bladder $(15,16)$, uterus $(17,18)$, and lung (19). Similar tumors showing a mixture of adenocarcinomatous and sarcomatous components do not appear to have been reported in the pancreas. However, a mixed tumor composed of a malignant islet cell tumor and rhabdomyosarcoma has been previously reported in the pancreas (8). The case reported by Ferreiro et al. (8) demonstrated a mixture of islet cell tumor and a sarcoma, which by light microscopy had the features of rhabdomyosarcomas. Although they were unable to demonstrate unequivocal cross-striations by ultramicroscopy, the sarcomatous component was desmin positive and Z-lines with thick filaments were seen on electron microscopy. We were unable to perform ultramicroscopy on our example 


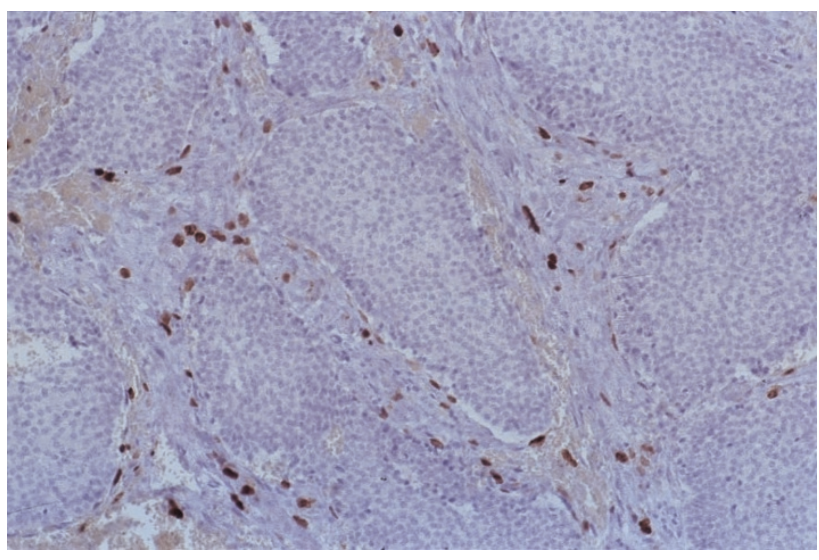

FIGURE 8. Topoisomerase II alpha stain highlighting the atypical spindle cell component's intimate association with the islet cell component. Note the atypical spindle cell component's extension into the fibrovascular connective tissue septa separating islet cell nests (immunoperoxidase, $\times 40$ ).

but immunohistochemistry demonstrated positive staining for desmin and smooth muscle actin consistent with a myogenous sarcoma. In the case reported by Ferreiro et al. (8), the neoplasm showed a transition from a traditional islet cell tumor to a small cell undifferentiated carcinoma to an area of rhabdomyosarcoma. Our case did not show such a transition, but rather the sarcomatous component presented as small discrete nodules and as an infiltrative process surrounding individual nests of islet cell tumor.

Several possible explanations exist for the occurrence of carcinosarcomas, including a collision tumor in which a distinctly separate carcinoma collides with a sarcoma resulting in a grossly single mass with two discrete entities. This possibility appears unlikely in our case, as well as in that reported by Ferriero et al. (8), because our example demonstrated an intimate admixture of the sarcomatous and neuroendocrine components. The previously reported case demonstrated a transition between classic islet cell tumor and sarcoma via undifferentiated carcinoma.

A second possibility is that the sarcomatous component is in reality a spindle cell carcinoma simulating a myogenous sarcoma. Arguing against this hypothesis is the clear demonstration of desmin and smooth muscle actin in many of the neoplastic cells of our case. This makes it highly unlikely that the spindle cell component is carcinomatous in nature.

A final possibility in the present case is that the myogenous component represents entrapped muscle. However, the clearly anaplastic nature of some of the cells as well as the high topoisomerase levels within these same cells supports a true sarcomatous differentiation.

Of interest is the observation that both our case and that previously reported (8) showed myoge- nous differentiation within the sarcomatous component. In addition, the majority of primary pancreatic sarcomas have been leiomyosarcomas (1-7). This suggests that mesenchymal malignancies arising within the pancreas may have a proclivity toward myogenous differentiation. We are unable to proffer an explanation for this observation.

Although our case did not present with metastatic disease, foci of lymphatic and vascular invasion were recognized within the tumor. Our follow-up period is too short to assess long-term prognosis. The previously reported combined malignant islet cell tumor and rhabdomyosarcoma demonstrated widespread metastases at the time of recognition, and the patient continued to suffer from hypercalcemia despite chemotherapy and operative debulking. The patient was alive at the time of the case report. The prognosis of our patient must remain guarded due to the presence of lymphovascular invasion and the high topoisomerase labeling index within the sarcomatous component of the neoplasm. Topoisomerase is a marker of the cell cycle and high labeling indices are generally associated with an aggressive course. The true prognosis of these rare combined islet cells tumors/ myosarcomas await the recognition and long-term follow-up of additional cases.

In conclusion, we report the second case of myosarcomatous differentiation in an islet cell tumor. This example and the previously reported one expand the morphologic spectrum of islet cell tumors of the pancreas. Because of the short-term follow-up in both our case and that reported by Ferriero et al. (8), we are unable to speculate on the long-term prognosis of these mixed tumors.

\section{REFERENCES}

1. Baylor SM, Berg JW. Cross-classification and survival characteristics of 5000 cases of cancer of the pancreas. J Surg Oncol 1973;5:335-58.

2. Berman JK, Leven N. Sarcoma of the pancreas. AMA Arch Surg 1996;73:894-6.

3. Carda AP, Hebrero SM, Benita L, Rodriguez A, Moreno G. Pancreas leiomyosarcoma associated with pseudocysts. Rev Esp Enferm Apar Dig 1976;48:731-8.

4. Feinberg SB, Margulis AR, Lober P, Roentgen. Findings in leiomyosarcoma of the pancreas. Minn Med 1957;36:505-6.

5. Ishikawa O, Iwanaga T, Matsui Y, Terasawa T, Aoki Y, Wada A. Leiomyosarcoma of the pancreas. Report of a case and review of the literature. Am J Surg Pathol 1981;5:597-602.

6. Oyamada C, Abe M, Masuya T, Nagamitsu S, Maeda Y. A case of leiomyosarcoma of the pancreas with a cystic-formation. Diag Theo (Jpn) 1970;58:155-8.

7. Ross CF. Leiomyosarcoma of the pancreas. Br J Surg 1951; 39:53-6.

8. Ferreiro J, Lewin K, Herron RM, Bhuta S. Malignant islet cell tumor with rhabdomyosarcomatous differentiation. AJ SP 1989;13:422-7.

9. Griffiths DFR, Jasani B, Newman GR, Williams ED, Williams GT. Glandular duodenal carcinoid — a somatostatin rich tumor with neuroendocrine associations. J Clin Pathol 1984;37:163-9. 
10. Mark EJ, Quay SC, Dickersin GR. Papillary carcinoid tumor of the lung. Cancer 1981;48:316-24.

11. Stanely RJ, DeSanto LW, Weiland LH. Oncocytic and oncocytoid carcinoid tumors (well-differentiated neuroendocrine carcinomas) of the larynx. Arch Otolaryngol Head Neck Surg 1986;112:529-35.

12. Markel SF, Abell MR, Haight C, French AJ. Neoplasms of bronchus commonly designated as adenomas. Cancer 1964; 17:590-608.

13. Petrelli M, Tetangco E, Reid JD. Carcinoma of the colon with undifferentiated carcinoid and squamous cell features. Am J Clin Pathol 1981;75:581-4.

14. Rosai J, Levine G, Weber WR, Higa E. Carcinoid tumors and oat cell carcinomas of the thymus. Pathol Annu 1976;11:201-6.
15. Young RH. Carcinoma of the urinary bladder. Cancer 1987; 59:1333-9.

16. Bloxham CA, Bennet MK, Robinson MC. Bladder carcinomas: three cases with diverse histogenesis. Histopathology 1990;16:63-7.

17. Norris HJ, Roth E, Taylor HB. Mesenchymal tumors of the uterus. II A clinical and pathological study of thirty one mixed mesodermal tumors. Obstet Gynecol 1996;26:57-63.

18. Chuang JT, van Velden VIJ, Grahm JB. Carcinomas and mixed mesodermal tumor of the uterine corpus: a review of 49 cases. Obstet Gynecol 1970;35:759-80.

19. Davis MP, Egan RT, Weiland LH. Carcinoma of the lung: Mayo Clinic experience and response to chemotherapy. Mayo Clin Proc 1984;59:598-603. 